\title{
Pathways, Processes, and Candidate Drugs Associated with a Hoxa Cluster-Dependency Model of Leukemia
}

\author{
Laura M. Kettyle ${ }^{1}$, Charles-Étienne Lebert-Ghali ${ }^{2,3}$, Ivan V. Grishagin ${ }^{1}$, Glenda J. Dickson ${ }^{4}(0$, \\ Paul G. O'Reilly ${ }^{1}$, David A. Simpson ${ }^{5}$, Janet J. Bij1 ${ }^{2,6}{ }^{\circledR}$, Ken I. Mills ${ }^{1}$, Guy Sauvageau ${ }^{6,7,8}$ and \\ Alexander Thompson 1,9,* \\ 1 Centre for Cancer Research and Cell Biology, Queen's University Belfast, Belfast BT9 7AE, UK; \\ lkettyle01@qub.ac.uk (L.M.K.); grishagin@gmail.com (I.V.G.); paul.oreilly@philips.com (P.G.O.); \\ k.mills@qub.ac.uk (K.I.M.) \\ 2 Maisonneuve-Rosemont Hospital Research Center, Montréal, QC H1T 2M4, Canada; \\ charles-etienne.lebert-ghali@umontreal.ca (C.-É.L.-G.); janettabijl@gmail.com (J.J.B.) \\ 3 Department of Microbiology, Infectious Disease and Immunology, Université de Montréal, Montréal, QC \\ H3A 2B4, Canada \\ 4 King's College London, Division of Cancer Studies, London WC2R 2LS, UK; glenda.dickson@kcl.ac.uk \\ 5 Centre for Experimental Medicine, Queen's University Belfast, Belfast BT9 7BL, UK; \\ David.Simpson@qub.ac.uk \\ 6 Department of Medicine, Université de Montréal, Montréal, QC H3G 2M1, Canada; \\ guy.sauvageau@umontreal.ca \\ 7 Division of Hematology, Maisonneuve-Rosemont Hospital, Montreal, QC H1T 2M4, Canada \\ 8 Institute for Research in Immunology and Cancer, Université de Montréal, Montréal, QC H3T 1J4, Canada \\ 9 University of Nottingham Biodiscovery Institute, Division of Cancer and Stem Cells, University of \\ Nottingham, Nottingham NG7 2UH, UK \\ * Correspondence: Alex.Thompson@nottingham.ac.uk
}

Received: 7 November 2019; Accepted: 13 December 2019; Published: 17 December 2019

\begin{abstract}
High expression of the HOXA cluster correlates with poor clinical outcome in acute myeloid leukemias, particularly those harboring rearrangements of the mixed-lineage-leukemia gene (MLLr). Whilst decreased HOXA expression acts as a readout for candidate experimental therapies, the necessity of the HOXA cluster for leukemia maintenance has not been fully explored. Primary leukemias were generated in hematopoietic stem/progenitor cells from Cre responsive transgenic mice for conditional deletion of the Hoxa locus. Hoxa deletion resulted in reduced proliferation and colony formation in which surviving leukemic cells retained at least one copy of the Hoxa cluster, indicating dependency. Comparative transcriptome analysis of Hoxa wild type and deleted leukemic cells identified a unique gene signature associated with key pathways including transcriptional mis-regulation in cancer, the Fanconi anemia pathway and cell cycle progression. Further bioinformatics analysis of the gene signature identified a number of candidate FDA-approved drugs for potential repurposing in high HOXA expressing cancers including MLLr leukemias. Together these findings support dependency for an MLLr leukemia on Hoxa expression and identified candidate drugs for further therapeutic evaluation.
\end{abstract}

Keywords: HOXA cluster; MLL-rearrangement; conditional deletion; leukemia maintenance; gene signature; pathways; candidate drugs

\section{Introduction}

The mixed lineage leukemia gene $(M L L)$ encodes a $431 \mathrm{kD}$ multifunctional protein recently re-designated as lysine-specific methyltransferase 2A (KMT2A). Gene rearrangements involving $M L L$, 
termed $M L L r$, are among the most potent oncogenic drivers of leukemia detected in over $70 \%$ of acute lymphoblastic (ALL), up to 50\% of acute myeloid leukemia (AML) cases in infants [1-4] and approximately $10 \%$ of adult leukemia including refractory therapy-related cases [5-8]. Currently, there are no specific therapies approved for $M L L r$ and identifying target and pathway dependencies is critical to improving clinical outcome for these patients.

The Class I homeobox (Hox) genes are well established as downstream targets of MLL, conserved from the ancestral Drosophila melanogaster orthologs HOM-C complex and Trithorax respectively [9-13]. In conjunction with polycomb repressor complex (PRC) proteins, MLL has an essential role in embryogenesis and definitive hematopoiesis through maintenance of Hox gene expression and instigation of progenitor cell proliferation and differentiation [14-16]. Complete knockout of $M l l$ is embryonic lethal in mice due in part to loss of Hoxa7, Hoxa9, and Hoxc9, and heterozygous Mllwtexhibit hematopoietic abnormalities, retarded growth and deformities of the axial skeleton due to dysregulated Hox expression [13,17]. Mll was also shown to be required for normal hematopoietic stem and progenitor cell (HSPC) activity in conditional knock-out models [18,19]. In human, high expression of HOXA cluster genes, is a hallmark of high-risk, refractory AML, particularly MLLr leukemias [16,20-24] and direct binding of MLL-fusion proteins to HoxA promoter regions results in increased expression of these genes in leukemic models [25].

Whilst several studies indicate a need for Hoxa expression, primarily Hoxa9, in the establishment of $M L L r$ leukemia their absolute requirement for disease progression and maintenance is less clear [26-28]. To address this, a MLL-AF9 AML transplantation model (MA9) was generated in a previously reported conditional Hoxa cluster (Hoxa $\left.{ }^{\text {flox/flox }}\right)$ background [29]. Homozygous deletion of the Hoxa cluster was not tolerated by MLL-AF9. However, significant reduction in expression of Hoxa7, Hoxa9, Hoxa10, and Hoxa11 was demonstrated and a Hoxadel gene signature including upregulation of Mpo, Clk-1, Clk-4, and Ccl6 and downregulation of Angpt1, Emerin, Ddx6, and IL31ra was obtained. Gene set enrichment and associated bioinformatics analysis of the Hoxa ${ }^{\text {del }}$ signature identified enriched processes including transcriptional repressor activity, myeloid, monocytic and leukemia differentiation, and canonical pathways including transcriptional mis-regulation in cancer and the Fanconi anemia pathway. Further bioinformatics analysis using connectivity mapping identified candidate drugs for potential repurposing in HOXA expressing cancer models including $M L L r$ and associated leukemias.

\section{Results}

\subsection{Establishment and Validation of Conditional Hoxa Leukemia Models}

Fresh HSPCs enriched from bone marrow of Hoxa $a^{\text {flox/flox }}(\mathrm{AFF}), \mathrm{MxCre}^{+} / \mathrm{Hoxa}^{\text {flox/flox }}$ (MAFF), or control CD45.1 mice were transduced with MA9 to generate leukemias. Extended serial re-plating in methylcellulose selected for transformed HSPCs with high proliferation potential. Condensed granulocyte-macrophage colonies (CFU-GM) were produced from MA9 transduction and serial re-plating resulted in increased condensation of the colony (Figure 1A). Single colonies obtained from P3 cultures were used to generate cell lines. Transformed cells (P3-P5) were subsequently transplanted into sub-lethally irradiated recipient mice to generate leukemias. Recipient mice developed primary leukemias within reported time frames (Figure 1B) and immunophenotypes (Table S1). Secondary leukemias, generated from direct transplantation of primary leukemias, were more aggressive with all mice succumbing to death within 50 days accompanied by tissue infiltration and splenomegaly (Figure 1C,D). Comparative gene expression analysis demonstrated increased Hoxa expression in all MA9 leukemias generated, compared to normal bone marrow (NBM), independent of the genetic background (Figure 2). 


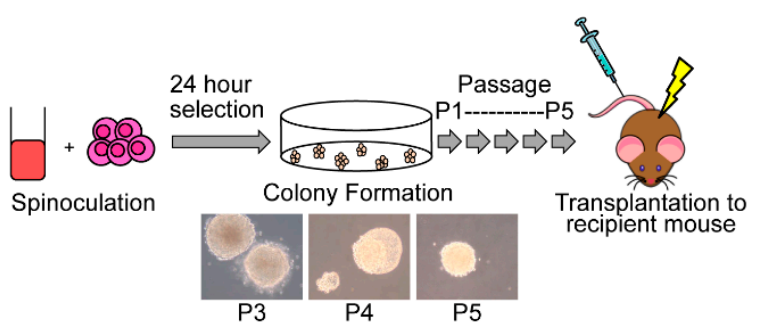

B

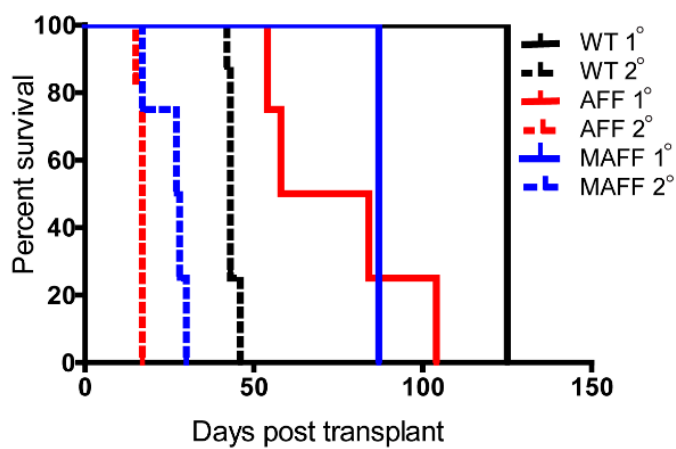

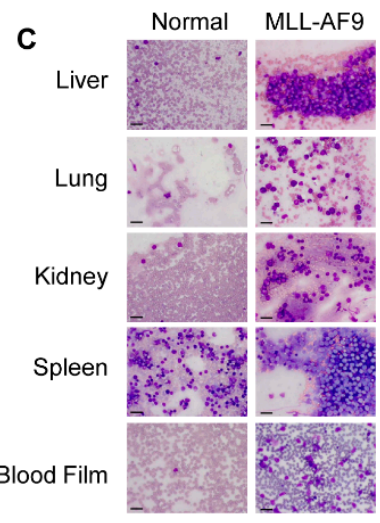

D

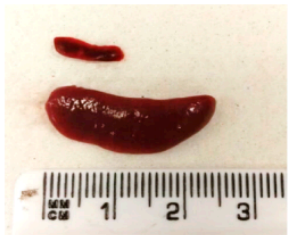

Figure 1. Development of MLL-AF9 (MA9) leukemias. (A) Donor hematopoietic stem/progenitor cells (HSPCs) were spinoculated with MA9 retroviral particles and serially passaged in methylcellulose prior to transplantation into recipient mice. (B) Kaplan-Meier plot demonstrating survival of transplanted mice receiving MA9 leukemic cells derived from $\mathrm{Hoxa}^{\text {flox/flox }}(\mathrm{AFF}), \mathrm{MxCre}^{+} / \mathrm{Hoxa}^{\text {flox/flox }}$ (MAFF) or control CD45.1 donor HSPCs. Primary transplants $\left(1^{\circ}\right)$ are denoted as solid lines, secondary transplants $\left(2^{\circ}\right)$ as dotted lines. (C) Microscope images of modified Wright's stained touch preps and peripheral blood smears of age-matched control (Normal) or leukemic (MLL-AF9) tissues derived from Hoxa flox/flox mice. Scale bar $20 \mu \mathrm{m}$. (D) Digital image of spleens removed from an age-matched control mouse (upper) and leukemic (MLL-AF9) Hoxa $a^{\text {flox/flox }}$ mouse (lower).

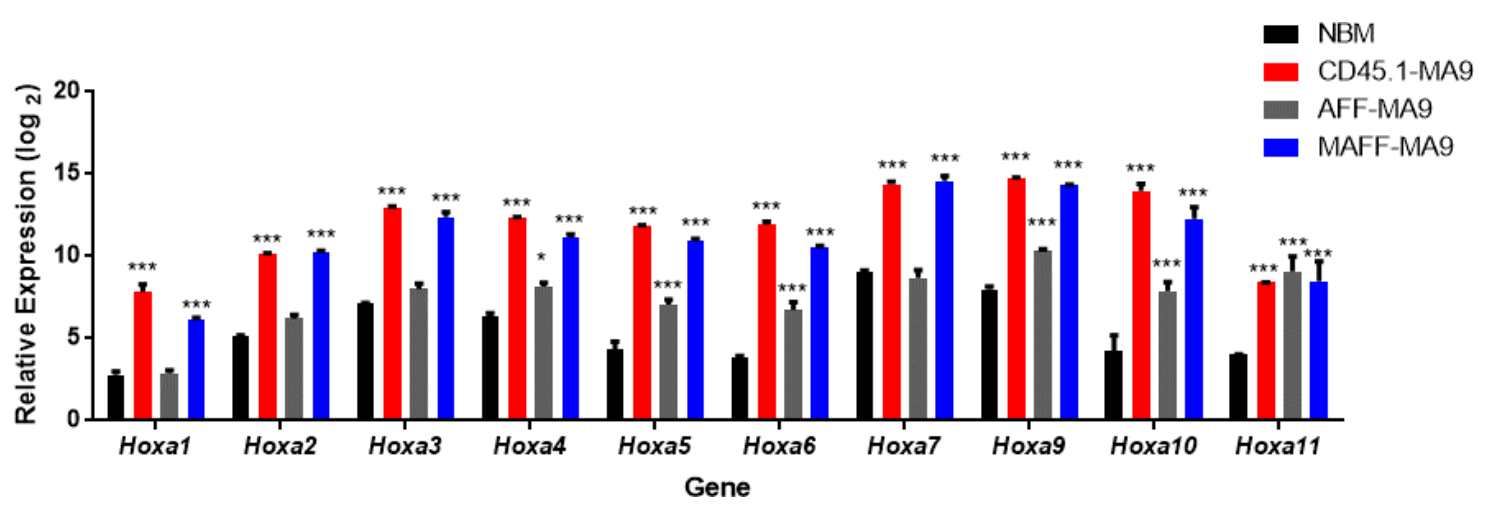

Figure 2. Overexpression of Hoxa cluster genes in MA9 leukemias. Bar chart of relative gene expression of Hoxa cluster genes in normal bone marrow (NBM) and MA9 leukemias derived from wild type (CD45.1-MA9), Hoxa ${ }^{\text {flox/flox }}$ (AFF-MA9) and MxCre ${ }^{+} / \mathrm{Hoxa}^{\text {flox/flox }}$ (MAFF-MA9) genetic backgrounds. The mean values from triplicate experiments are plotted. Significance as calculated by 1 way ANOVA compared to control bone marrow is denoted as ${ }^{*} p \leq 0.05 ;{ }^{* *} p \leq 0.01,{ }^{* * *} p \leq 0.001$.

\subsection{Reduced Leukemia Colony Formation Following IFN $\alpha$-Induced Hoxa Deletion}

Direct incubation with interferon-alpha (IFN $\alpha$ ) activated $C r e$ in the $M x-1$ background only and resulted in visible reduction in MAFF-MA9 colony formation compared to control CD45.1-MA9 cells or MAFF-derived NBM (Figure 3A upper panel). Direct colony counts demonstrated significant reduction in the number of colonies observed in MAFF-MA9 cells compared to PBS control and no 
measurable IFN $\alpha$ toxicity at the concentrations used (1U and 2.5U) in MAFF-derived NBM cells (Figure 3A lower panel).

A
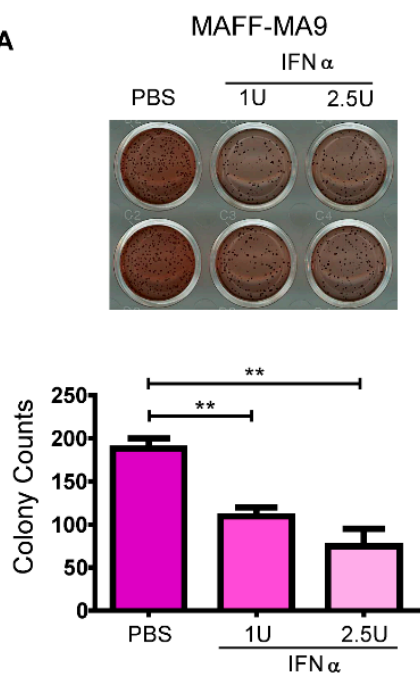

B

BULK CELLS

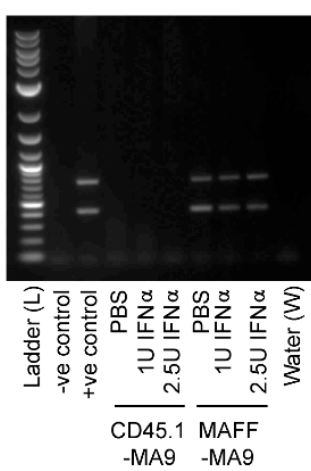

C

3' UTR mHoxa1

---ATTCCTAAGACTCCTCAACCTAGG---ATAACTTCGTATAGCATACATTATACGAAGTTAT---TCATGGTCTGCTACTTACGTCG-(Combined loxP site)

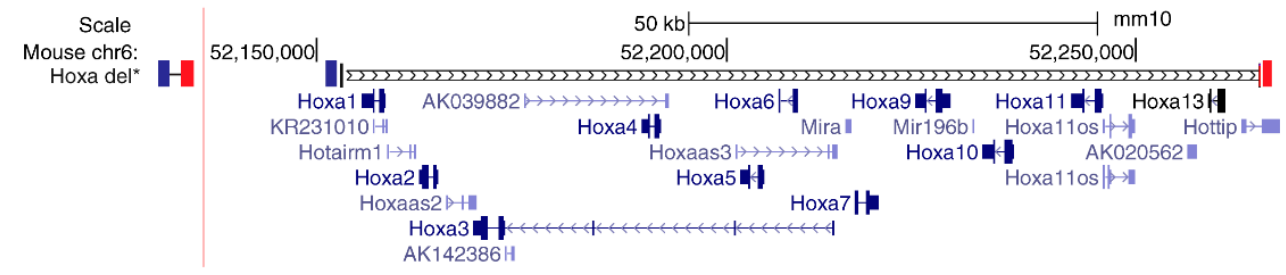

Figure 3. In vitro deletion of the Hoxa cluster in $\mathrm{MxCre} e^{+} / \mathrm{Hoxa}^{\text {flox/flox }}$ (MAFF) derived leukemic cells. (A) Digital images of leukemic colonies derived from MAFF-MA9 and wild type (CD45.1-MA9) mice compared to MAFF derived normal bone marrow controls (MAFF-NBM). Colonies were treated with interferon-alpha (IFN- $\alpha$ ) at the indicated dose units (U) or with PBS vehicle control (upper panel), counted after 7 days using the GelCount ${ }^{\mathrm{TM}}$ analyzer and plotted on a bar chart (lower panel). Not-significant (ns); ${ }^{* *} p \leq 0.01$. (B) Digital images of electrophoresed agarose gels containing PCR amplicons of expected size (arrows) derived from bulk CD45.1 or MAFF-derived leukemic colonies (left panel) or representative MAFF-MA9-derived individual colonies (right panel). (C) A schematic of the aligned Hoxa ${ }^{\mathrm{del}}$ amplicon sequence with the mouse chromosome 6 tract (UCSC). The sequencing read (-600 bp) encompassed a portion of the $3^{\prime}$ UTR of $m$ Hoxa1 (blue), the recombined loxP site (black) and apportion of the $5^{\prime}$ UTR of mHoxa13 (red). 
PCR analysis of gDNA obtained from MAFF-MA9 cells showed levels of the Hoxa ${ }^{\text {del }}$ amplicon equivalent with the Hoxa ${ }^{\mathrm{wt}}$ amplicon, presumably due to background Cre activation that was not markedly altered by IFN $\alpha$ treatment in bulk cells (Figure 3B, left panel). To explore the possibility that Hoxa $a^{\text {del/del }}$ cells were out-competed by their Hoxa ${ }^{\mathrm{del} / \mathrm{wt}}$ counterparts in bulk cultures, 100 individual MAFF-MA9 colonies from each treatment were picked and assayed by PCR. All 100 colonies demonstrated retention of at least one copy of the Hoxa cluster that had been unaffected by IFN $\alpha$-treatment (sample gel Figure 3B, right panel). Isolation of the Hoxa ${ }^{\text {del }}$ amplicon followed by Sanger sequencing confirmed deletion of the loci spanning $100 \mathrm{~kb}$ (Figure $3 \mathrm{C}$ and Figure S1).

\subsection{Extension in Survival Following In Vivo Deletion of Hoxa Cluster}

To examine whether propagation of the leukemia was dependent on maintained Hoxa expression engrafted mice that received IFN $\alpha$ - or PBS-treated MAFF-MA9 leukemic cells were further treated in vivo with Poly I:C (Figure 4A). A significant increased survival following Poly I:C treatment was observed compared to PBS controls (Figure 4B). All control mice succumbed to disease by 21 days, whereas Poly I:C treated mice survived up to day 26, indicative of reduction in number or function of leukemia repopulating cells (LRCs) due to in vivo Hoxa deletion. A significant increase in survival was also observed in cells that had been pre-treated, ex vivo, with IFN $\alpha$ compared to PBS (Figure 4B). Additional treatment of these cells with Poly I:C did not further increase survival suggesting that LRCs that escape Hoxa deletion are refractory to further Cre-treatment. In addition, reduced leukemia burden was observed in an independent (MAFF-MA9-Luc+) cohort of transplanted NOD-scid IL2rynull (NSG) mice using bioimaging (Figure 4C). Recipient mice that succumbed to leukemia from either treatment arm retained the Hoxa ${ }^{\text {wt }}$ allele (Figure S2).

A

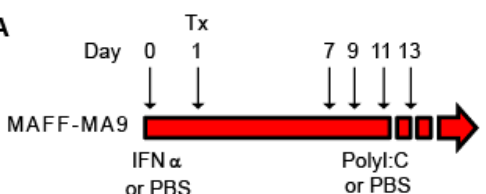

Day 4
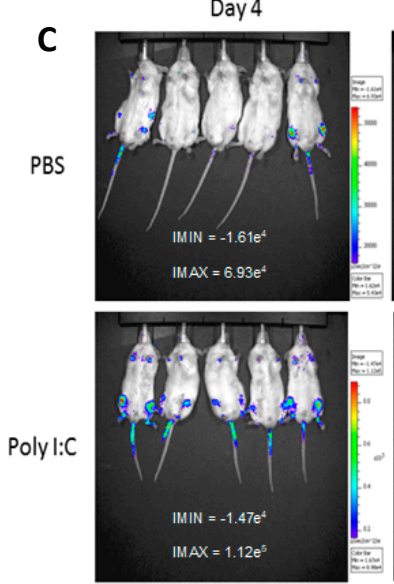

B

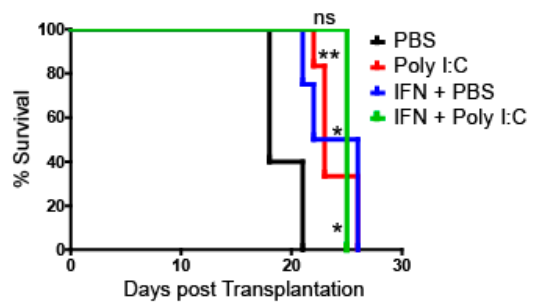

Day 19

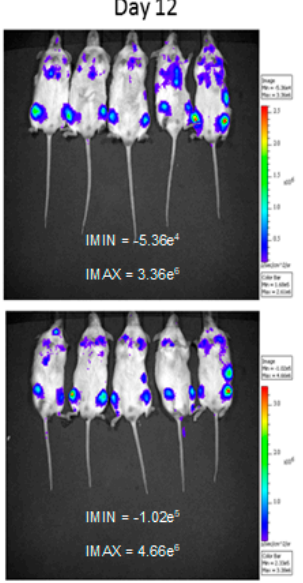

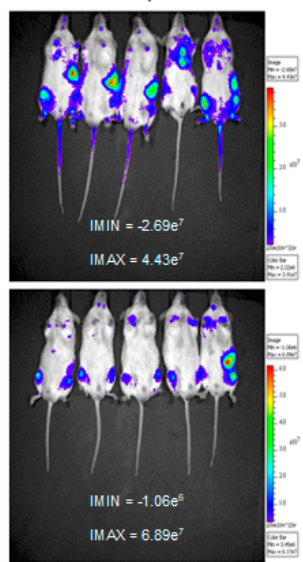

Figure 4. In vivo treatment of MAFF-MA9 leukemia. (A) Schematic of the treatment of MAFF-MA9 leukemias prior to and following transplantation into recipient mice. Interferon-alpha (IFN- $\alpha$ ), Polyinosinic:polycytidylic acid (PolyI:C), vehicle (PBS). (B) Kaplan-Meier plot demonstrating survival of transplanted mice receiving MAFF-MA9 leukemia cells following treatment. ${ }^{*} p \leq 0.05 ;{ }^{* *} p \leq 0.01$. (C) In Vivo Imaging Systems (IVIS) derived images of luciferase expressing MAFF-MA9 transplanted into NOD-scid IL2rynull (NSG) recipient mice. Mice were treated with PBS or PolyI:C and live images taken as indicated ( $n=5$ per group). 


\subsection{Hoxadel Signature and Associated Pathways}

Due to the potential loss of Hoxadel cells over time, Illumina BeadArray-based gene expression profiling was performed on freshly sorted Cre-GFP and GFP-control treated AFF-MA9 cells. Methylcellulose-based colony formation and PCR demonstrated efficient deletion of the Hoxa locus (Figure S4). Overall output was characterized by plotting significance in the form of negative $\log 10$ (Adjusted $p$-value) versus log2 expression (fold change) for each gene (Figure 5). Genes with - $\log 10$ (Adjusted $p$-value) $>2$ and $\log 2$ (fold change) $>0.5$ were considered differentially expressed. Transcripts induced or repressed at $\log 2$ fold change $\geq 0.5 ; p \leq 0.05$ were sorted in ascending order by adjusted P-value. One hundred and fifty three probes, representing 135 differentially expressed genes (Table S2) were identified for further bioinformatics evaluation.
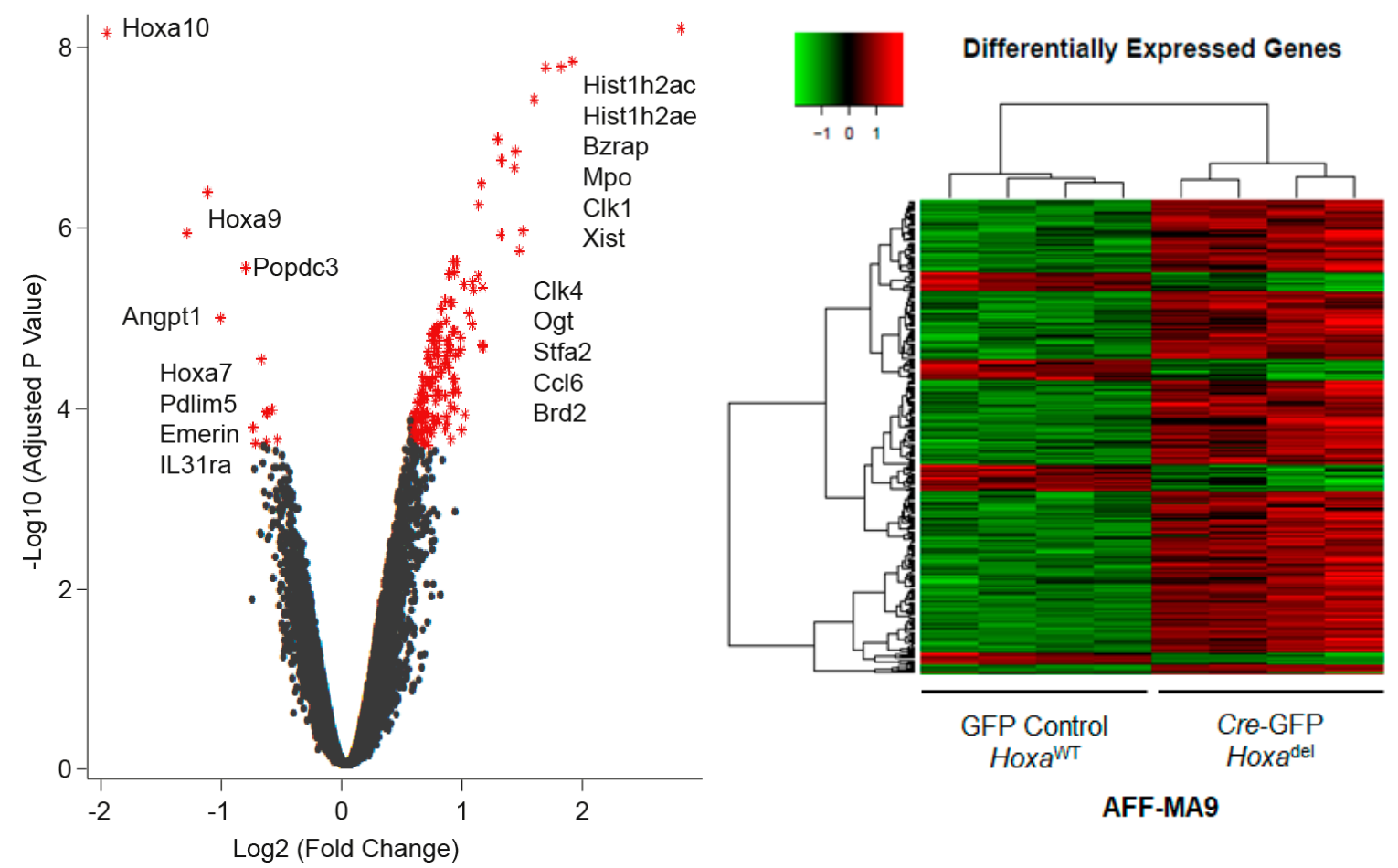

Figure 5. Differential gene expression in Hoxa ${ }^{\text {del }}$ MA9 cells. Left panel; Volcano plot of significance for each of 24,326 probes from Cre-GFP treated (Hoxa ${ }^{\text {del }}$ ) AFF-MA9 cells. Negative log10 (Adjusted P-value) versus $\log 2$ (fold change) compared to GFP-treated AFF-MA9 cells. Genes with $-\log 10$ (Adjusted P-value) $>2$ and $\log 2$ (fold change) $>0.5$ (annotated and highlighted in red) were considered differentially expressed. Right panel; sample transcripts induced or repressed at log2 (fold change) of 0.5 or more $(p \leq 0.05)$ were subjected to unsupervised hierarchical agglomerative clustering by treatment with Cre based on Euclidean distance and linkage.

\subsection{Gene Set Enrichment Analysis}

To identify candidate pathways, ontologies and drug interactions, differentially expressed genes were further analyzed by Enrichr [30,31] against curated data sets. In total, 151 probes representing 135 transcripts (123 increased expression, 12 decreased expression) met the criteria for analysis (log2 fold change $\geq 0.5 ; p \leq 0.05$ ). A summary of the analysis indicates a role for the Hoxa cluster in key biological processes and pathways (Figure 6). Cross reference of the Hoxa ${ }^{\text {del }}$ signature to the NCBI drug signatures database for gene set analysis (DSigDB) identified several candidate drugs, previously shown to have reported effects in other cancers, for repurposing in HOXA-associated leukemia. 


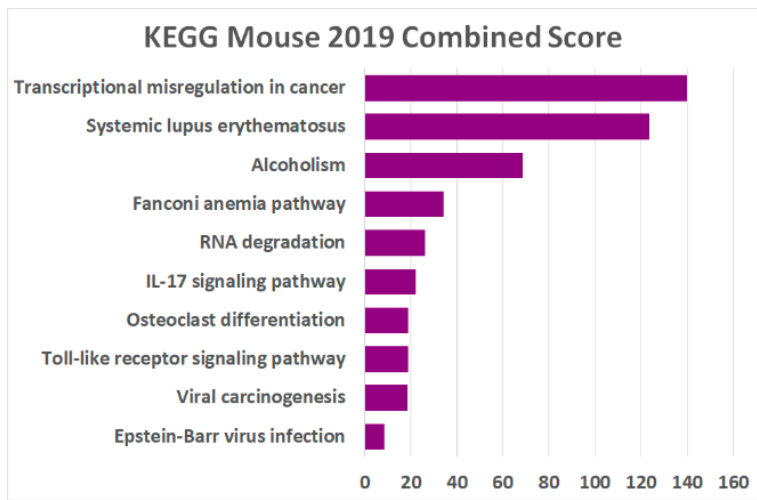

GO Biological Process 2018

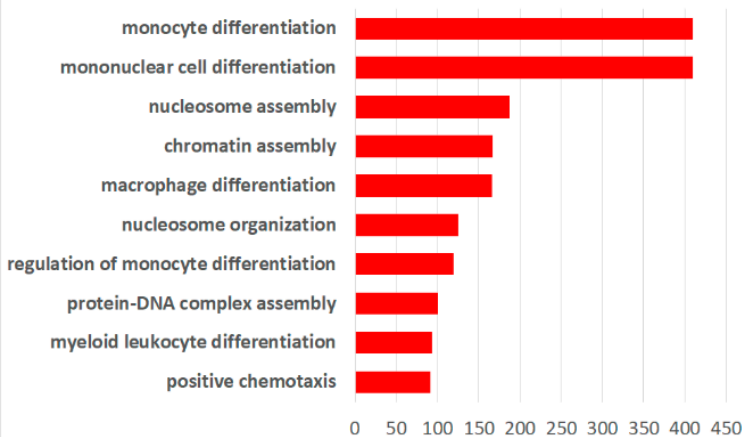

DSigDB Combined Score

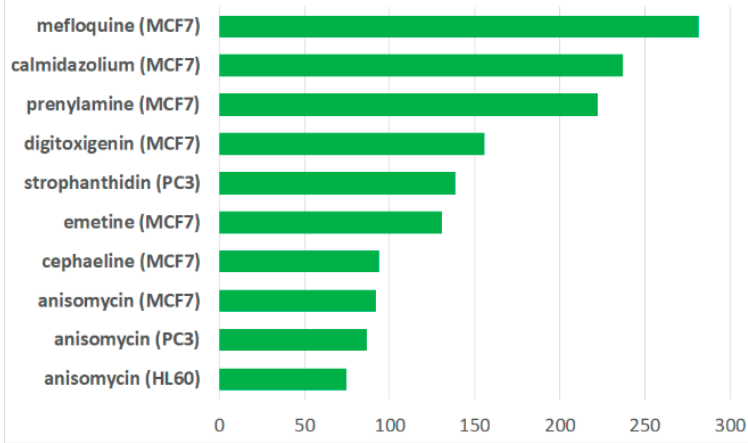

GO Molecular Function 2018

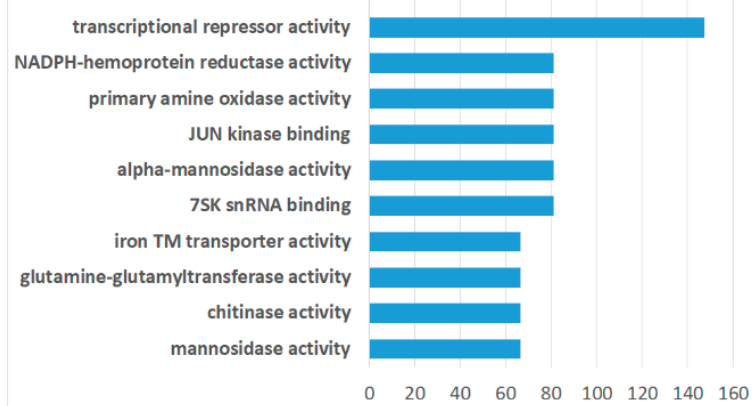

Figure 6. Gene set enrichment analysis of the Hoxa ${ }^{\text {del }}$ signature. Summary bar charts demonstrating association of the Hoxa ${ }^{\text {del }}$ signature with databases including Kyoto Encyclopedia of Genes and Genomes (KEGG) pathways, Gene Ontology (GO) of Molecular Function and Biological processes and the NCBI drug signatures database for gene set analysis (DSigDB) using Enrichr [30,31]. Combined scores (based on the log Fisher exact test $p$-value and $z$-score for deviation from expected rank) are plotted against the key pathway, process or drug interactions.

\section{Discussion}

The clinical impact of targeted therapy against oncogenic dependency is exemplified by successful treatment of chronic myeloid leukemia (CML) with tyrosine kinase inhibitors (TKIs). In a large cohort study $(n=2662)$ life expectancy of CML patients that respond to TKIs was reported to approach the life expectancy of the general population [32]. Similar approaches to develop effective targeted therapies for other cancers are ongoing for which identification of oncogenic dependency pathways and processes is a prerequisite.

The association of deregulated HOX gene expression with cancer is well established (reviewed by Grier et al. [33]) particularly in aggressive forms such as acute leukemias (reviewed by Alharbi et al. [34]) in which the Hoxa cluster is predominant. Loss- and gain-of-function studies have identified roles for individual Hoxa genes with normal hematopoiesis including regulation of lineage commitment $[35,36]$, development [37,38], self-renewal, and stem cell expansion [39-41]. However, the need for continuous HOXA expression in leukemia initiation and progression remains unclear $[26,28,42,43]$. This is due in part to functional redundancy within the HOX network and the potential oncogenic roles of non-coding elements within the HOXA locus including HOTTIP [44] and HOXA-AS2 [45].

Herein, we demonstrate the criticality of the Hoxa cluster in the maintenance of established and aggressive MA9 leukemia in a murine model. Conditional Cre-recombinase based deletion of the Hoxa locus resulted in loss of leukemic phenotype in vitro and extension of survival in vivo. This phenotype was associated with differential expression of the Hoxa cluster, primarily Hoxa7-Hoxa11. Resistant leukemias and colonies retained one allele of the Hoxa locus, instead of upregulating paralogs, reflective of an 'escapee' rather than a 'functional redundancy' phenotype. Transplantation 
of Hoxa ${ }^{\text {del }}$ cells resulted in extension in time to leukemia. In contrast to the normal hematopoiesis setting, which tolerates biallelic deletion of the Hoxa locus, albeit with reduced HSPC proliferation and self-renewal [46] biallelic deletion was not tolerated in MA9 cells and all subsequent single-cell generated colonies retained at least one allele of the Hoxa locus. Together, this demonstrates unique dependency on a subset of the Hoxa cluster (Hoxa7, Hoxa9, Hoxa10, and Hoxa11) genes for maintenance of MA9 leukemia.

In association with the well-defined role for $H O X$ in transcription regulation, hematopoietic stem cell self-renewal and maturation, several zinc finger, histone, cell cycle (e.g., Clk-1, Clk-4) and blood cell marker (e.g., $M p o$ ) genes were over expressed following Hoxa cluster deletion. In combination with Hoxa7, a9, and a10, reduced expression of endothelial/adhesion molecules (Heg1 and Angptl1) may be associated with altered Hoxa ${ }^{\text {del }}$ cell-niche interactions.

Bioinformatics analysis of the Hoxa ${ }^{\text {del }}$ gene signature identified significant enrichment of biological processes associated with blood cell differentiation, nucleosome association and chromatin assembly along with molecular functions including transcription repressor activity. The key pathway associated with the Hoxa ${ }^{\text {del }}$ signature was transcriptional misregulation in cancer. Several drugs with anti-cancer properties reported for solid tumors including, Mefloquine in glioblastoma [47], Digitoxigenin in renal carcinoma [48] and Emetine in bladder cancer [49] were associated with the Hoxa ${ }^{\text {del }}$ signature. Furthermore, some of these drugs e.g., Emetine and Cephaline were recently shown to be highly active against primary chronic lymphocytic leukemia cells by repressing HIF-1 $\alpha$ and disturbing intracellular redox homeostasis [50].

The most represented $(n=3)$ compound in the top 10 DSigDB drugs associated with the $H o x a^{\text {del }}$ signature, Anisomycin, was recently identified as an expression mimic of mutant RUNX-1 (mt-RUNX-1) knockdown with specific potency against cells from AML patients with germline or somatic $m t-R U N X-1$ [51]. This is of particular interest as wild type RUNX-1 is essential for the maintenance of MLL-AF9 leukemia [52]. It is intriguing to postulate that upregulation of the HOXA cluster, central to progression in the most refractory AML subtypes and aggressive forms of cancer, is potentially druggable by such loss of expression mimics. Further analysis of the efficacy of such drugs across cell lines and patient samples in conjunction with toxicity profiles against normal cells is warranted to identify and de-risk candidates for potential clinical application.

\section{Materials and Methods}

\subsection{Mouse Strains}

Hoxa ${ }^{\text {flox/flox }}$ [46], MxCre, C57Bl/6-Ly5.1/CD45.1, C57Bl/6J/CD45.2 (Charles River, Harlow, UK) and generated compound $\mathrm{MxCre} / \mathrm{Hoxa} a^{\text {flox/flox }}$ (MAFF) mice were maintained in SPF facilities under guidelines of The UK Animals (Scientific Procedures) Act 1986. Experimental procedures under PPL2760 were approved by the QUB Ethical Review Board and age-matched randomized animals were used throughout. Genotyping of litters was achieved by PCR (Figure S3, Table S3).

\subsection{Generation of Primary Leukemias and Cell Lines}

Mouse hematopoietic stem and progenitor cells (HSPCs) isolated from bone marrow (Cat\# 19856, EasySep $^{\text {TM }}$, STEMCELL Technologies, Cambridge, UK) were pre-stimulated overnight in RPMI1640/10\% FCS/2 mM L-Glutamine (Life Technologies, Paisley, UK) supplemented with $10 \mathrm{ng} / \mathrm{mL}$ each of IL-3, IL-6, GM-CSF and $100 \mathrm{ng} / \mathrm{mL}$ SCF. Pre-stimulated HSPCs were transduced with MSCV-based retroviral (MLL-AF9, Cre-GFP and GFP control) or SFFV-based lentiviral supernatants (pSLIEW) as previously described [53,54]. Transduced HSPCs $\left(1 \times 10^{4}\right.$ cells) seeded in Methocult M3434 (Stem Cell Technologies, Cambridge, UK) and re-plated every 6 days. Primary clonal cell lines were generated from third round re-plating and cultured in RPMI media containing $5 \mathrm{ng} / \mathrm{mL}$ each of IL-3, IL-6, GM-CSF, and $50 \mathrm{ng} / \mathrm{mL}$ SCF. Primary leukemias developed in sub-lethally (450-600 cGy) irradiated recipient mice were 
immunophenotyped by flow cytometry analysis (BD LSR II platform; BD Biosciences, Indianapolis, IN, USA) using established protocols and antibodies.

\subsection{Deletion of the Hoxa Cluster}

In vitro deletion of the Hoxa locus was by IFN $\alpha$ (R\&D Systems, Abingdon, UK) treatment at the indicated dose and time. In vivo deletion in MAFF-MA9 leukemic mice was achieved by intraperitoneal (IP) injection of Polyinosinic:polycytidylic acid (Poly I:C; GE Healthcare Life Sciences, Buckinghamshire, UK) as previously described [46]. Briefly, mice were given $10 \mu \mathrm{g} / \mathrm{g}$ Poly I:C or vehicle (PBS) up to a maximum of $250 \mu \mathrm{g} /$ mouse. Ex vivo deletion was by direct exposure to MSCV-Cre-GFP or MSCV-GFP control retroviral supernatants followed by cell sorting and gene expression profiling. Mice transplanted with traceable (pSLIEW) leukemias were injected IP with $150 \mathrm{mg}$ D-luciferin $/ \mathrm{kg}$ (Gold Biotechnology, St. Louis, MO, USA) and imaged using the Xenogen IVIS 200 (PerkinElmer, Buckinghamshire, UK). Nested PCR was used to identify individual colony bands.

\subsection{Gene Expression Analysis and Bioinformatics}

Total RNA was isolated using Trizol ${ }^{\circledR}$ (Life Technologies), and its quality was assessed using Agilent RNA 6000 Nano chip and Agilent 2100 Bioanalyzer (Agilent Technologies, Santa Clara, CA, USA) according to the manufacturer's instructions. RNA integrity (RIN) values of $>9$ were obtained for all samples prior to application to the Mouse Ref-8 expression v.2 BeadArray (Illumina, San Diego, CA, USA), according to the manufacturer's instructions and as previously reported [55]. Briefly, $550 \mathrm{ng}$ of each RNA was reverse transcribed then in vitro transcribed to generate biotinylated cRNAs. Aliquots of labelled cRNAs (750 ng) were then hybridized to the BeadArray for $16-18 \mathrm{~h}$ at $58^{\circ} \mathrm{C}$. Signal detection was achieved using Amersham fluorolink streptavidin-Cy3 (GE Healthcare Bio-Sciences, Little Chalfont, UK) and scanned images obtained using the Illumina BeadArray confocal scanner. Bead level data of biological triplicates were transformed to $\log 2$ scale, normalized (quantile method) using beadarray R package [56] and annotated (Gene Symbols, Names, Entrez IDs, and Probe Quality Grades) using illuminaMousev2.db R package. Probes with poor quality grades (and Pgk-1 positive control for Cre-treatment) were removed. Differential expression was assessed by linear regression followed by parametric empirical Bayes analysis using limma R package [57] and output obtained by plotting significance versus $\log 2$ expression (fold change). Genes with expression ratios above log2 (0.5)-fold between treatments and control $(p<0.05$ and $p<0.01)$ were identified. False discovery rates (FDR) were controlled using the Benjamini-Hochberg algorithm. Hierarchical clustering with complete linkage and Euclidean distance was performed. The Hoxa ${ }^{\text {del }}$ signature obtained was submitted as a fuzzy list to the Enrichr platform $[30,31]$ to identify association with 156-curated libraries. Outputs were tabulated to show the Combined Score as a function of the log Fisher exact test $p$-value and $z$-score for deviation from expected rank plotted against the key pathway, process or drug interactions.

\subsection{Statistical Analysis}

Student's t-tests were performed using GraphPad Prism software v7.0 (GraphPad Software, La Jolla, CA, USA). Means \pm SEM were plotted and significance denoted by the value or as ${ }^{*} p \leq 0.05$; ** $p \leq 0.01$, *** $p \leq 0.001$ throughout.

\section{Conclusions}

In conclusion, our findings directly demonstrate, for the first time, absolute dependency on the Hoxa locus for the maintenance of MA9 leukemia and identifies molecular processes and key pathways for further analysis and candidate drugs for pre-clinical validation and redeployment to this highly refractory disease. Several of the candidates identified here, by association with a Hoxa ${ }^{\text {del }}$ phenotype, have demonstrated efficacy in a variety of cancer subtypes. Extension of these findings to other $M L L r$ leukemias or cancers associated with high HOXA expression warrants further investigation. 
Supplementary Materials: The following are available online at http://www.mdpi.com/2072-6694/11/12/2036/s1, Figure S1: Direct sequence validation of the Hoxa ${ }^{\text {del }}$ amplicon, Figure S2: Retention of the Hoxa cluster in treated MAFF-MA9 leukemic mice; Figure S3: Genotyping of $\mathrm{MxCre}+\mathrm{Hoxa}^{\text {flox/flox }}$ (MAFF) mice, Table S1: Representative Immunophenotype analysis of MLL-AF9 primary leukemias (PL) and cell lines (CL), Table S2: Hoxa ${ }^{\text {del }}$ signature (ranked), Table S3: List of oligomers used to define the genotype of experimental mice, bulk and individual colonies (nested).

Author Contributions: Conceptualization J.J.B. and A.T.; methodology, L.M.K., C.-É.L.-G., G.J.D., J.J.B. and A.T.; software, P.G.O. and I.V.G.; validation, L.M.K. and A.T.; formal analysis, L.M.K., K.I.M. and A.T.; investigation, L.M.K., G.J.D. and A.T.; resources, J.J.B., K.I.M., G.S. and A.T.; data curation, I.V.G., D.A.S. and A.T.; writing—original draft preparation, L.M.K. and C.-É.L.-G.; writing-review and editing, J.J.B. and A.T.; visualization, I.V.G., P.G.O. and K.I.M.; supervision, J.J.B., K.I.M., G.S. and A.T.; project administration, A.T.; funding acquisition, J.J.B., K.I.M. and A.T.

Funding: This research was funded in part by The American Cancer Society for Beginning Investigator Fellowship from the UICC to A.T. and was supported by Bloodwise (UK) grant no. 09035, Leukaemia and Lymphoma NI grants R2055CNR and R2054CNR and The Strategic Development Fund (STEM, School of Medicine, University of Nottingham). L.K. and G.D. were supported by Bloodwise, formerly Leukaemia Lymphoma Research (UK) and G.D. was a recipient of a Yamagiwa-Yoshida Memorial International Study Grant (UICC). L.K., I.V.G and K.I.M. were funded by Leukaemia Lymphoma NI, C.-E.L.-G and J.B were supported by the Canadian Cancer Society (\#20399), G.S. is a recipient of a Canada Research Chair in molecular genetics of stem cells and a scholar of the Leukemia Lymphoma Society of America Supported by NIH grant no. RO165430.

Acknowledgments: The authors wish to acknowledge Denis Duboule (University of Geneva, Geneva) and Marie Kmita (Institut de Recherches Cliniques de Montréal) for the Hoxaflox/WT mice. We are also grateful to John Dick (University of Toronto, Canada) and Olaf Heidenreich (Newcastle University, UK) for essential plasmids and Margaret Dellett for assistance with RNA library preparation. The authors also wish to thank the staff within the Biological Services Unit, Bioinformatics and Flow Cytometry Cores at Queen's University Belfast.

Conflicts of Interest: The authors declare no conflict of interest.

\section{References}

1. Chessells, J.M.; Harrison, C.J.; Kempski, H.; Webb, D.K.; Wheatley, K.; Hann, I.M.; Stevens, R.F.; Harrison, G.; Gibson, B.E. Clinical features, cytogenetics and outcome in acute lymphoblastic and myeloid leukaemia of infancy: Report from the MRC Childhood Leukaemia working party. Leukemia 2002, 16, 776-784. [CrossRef] [PubMed]

2. Muntean, A.G. Mechanisms of mixed-lineage leukemia. Int. J. Hematol. Oncol. 2013, 2, 207-217. [CrossRef] [PubMed]

3. Rubnitz, J.E.; Link, M.P.; Shuster, J.J.; Carroll, A.J.; Hakami, N.; Frankel, L.S.; Pullen, D.J.; Cleary, M.L. Frequency and prognostic significance of HRX rearrangements in infant acute lymphoblastic leukemia: A Pediatric Oncology Group study. Blood 1994, 84, 570-573. [CrossRef] [PubMed]

4. Tien, H.F.; Hsiao, C.H.; Tang, J.L.; Tsay, W.; Hu, C.H.; Kuo, Y.Y.; Wang, C.H.; Chen, Y.C.; Shen, M.C.; Lin, D.T.; et al. Characterization of acute myeloid leukemia with MLL rearrangements-no increase in the incidence of coexpression of lymphoid-associated antigens on leukemic blasts. Leukemia 2000, 14, 1025-1030. [CrossRef]

5. Felix, C.A. Leukemias related to treatment with DNA topoisomerase II inhibitors. Med. Pediatric Oncol. 2001, 36, 525-535. [CrossRef]

6. Pui, C.H.; Relling, M.V. Topoisomerase II inhibitor-related acute myeloid leukaemia. Br. J. Haematol. 2000, 109, 13-23. [CrossRef]

7. Schoch, C.; Schnittger, S.; Klaus, M.; Kern, W.; Hiddemann, W.; Haferlach, T. AML with 11q23/MLL abnormalities as defined by the WHO classification: Incidence, partner chromosomes, FAB subtype, age distribution, and prognostic impact in an unselected series of 1897 cytogenetically analyzed AML cases. Blood 2003, 102, 2395-2402. [CrossRef]

8. Super, H.J.; McCabe, N.R.; Thirman, M.J.; Larson, R.A.; Le Beau, M.M.; Pedersen-Bjergaard, J.; Philip, P.; Diaz, M.O.; Rowley, J.D. Rearrangements of the MLL gene in therapy-related acute myeloid leukemia in patients previously treated with agents targeting DNA-topoisomerase II. Blood 1993, 82, 3705-3711. [CrossRef]

9. Breen, T.R.; Harte, P.J. Molecular characterization of the trithorax gene, a positive regulator of homeotic gene expression in Drosophila. Mech. Dev. 1991, 35, 113-127. [CrossRef] 
10. Breen, T.R.; Harte, P.J. Trithorax regulates multiple homeotic genes in the bithorax and Antennapedia complexes and exerts different tissue-specific, parasegment-specific and promoter-specific effects on each. Development 1993, 117, 119-134.

11. Duboule, D.; Dolle, P. The structural and functional organization of the murine HOX gene family resembles that of Drosophila homeotic genes. EMBO J. 1989, 8, 1497-1505. [CrossRef] [PubMed]

12. Graham, A.; Papalopulu, N.; Krumlauf, R. The murine and Drosophila homeobox gene complexes have common features of organization and expression. Cell 1989, 57, 367-378. [CrossRef]

13. Yu, B.D.; Hanson, R.D.; Hess, J.L.; Horning, S.E.; Korsmeyer, S.J. MLL, a mammalian trithorax-group gene, functions as a transcriptional maintenance factor in morphogenesis. Proc. Natl. Acad. Sci. USA 1998, 95, 10632-10636. [CrossRef] [PubMed]

14. Butler, L.H.; Slany, R.; Cui, X.; Cleary, M.L.; Mason, D.Y. The HRX proto-oncogene product is widely expressed in human tissues and localizes to nuclear structures. Blood 1997, 89, 3361-3370. [CrossRef]

15. Ernst, P.; Mabon, M.; Davidson, A.J.; Zon, L.I.; Korsmeyer, S.J. An Mll-dependent Hox program drives hematopoietic progenitor expansion. Curr. Biol. 2004, 14, 2063-2069. [CrossRef]

16. Kawagoe, H.; Humphries, R.K.; Blair, A.; Sutherland, H.J.; Hogge, D.E. Expression of HOX genes, HOX cofactors, and MLL in phenotypically and functionally defined subpopulations of leukemic and normal human hematopoietic cells. Leukemia 1999, 13, 687-698. [CrossRef]

17. Yu, B.D.; Hess, J.L.; Horning, S.E.; Brown, G.A.; Korsmeyer, S.J. Altered Hox expression and segmental identity in Mll-mutant mice. Nature 1995, 378, 505-508. [CrossRef]

18. Jude, C.D.; Climer, L.; Xu, D.; Artinger, E.; Fisher, J.K.; Ernst, P. Unique and independent roles for MLL in adult hematopoietic stem cells and progenitors. Cell Stem Cell 2007, 1, 324-337. [CrossRef]

19. McMahon, K.A.; Hiew, S.Y.; Hadjur, S.; Veiga-Fernandes, H.; Menzel, U.; Price, A.J.; Kioussis, D.; Williams, O.; Brady, H.J. Mll has a critical role in fetal and adult hematopoietic stem cell self-renewal. Cell Stem Cell 2007, 1, 338-345. [CrossRef]

20. Abramovich, C.; Humphries, R.K. Hox regulation of normal and leukemic hematopoietic stem cells. Curr. Opin. Hematol. 2005, 12, 210-216. [CrossRef]

21. Armstrong, S.A.; Staunton, J.E.; Silverman, L.B.; Pieters, R.; den Boer, M.L.; Minden, M.D.; Sallan, S.E.; Lander, E.S.; Golub, T.R.; Korsmeyer, S.J. MLL translocations specify a distinct gene expression profile that distinguishes a unique leukemia. Nat. Genet. 2002, 30, 41-47. [CrossRef] [PubMed]

22. Dickson, G.J.; Liberante, F.G.; Kettyle, L.M.; O’Hagan, K.A.; Finnegan, D.P.; Bullinger, L.; Geerts, D.; McMullin, M.F.; Lappin, T.R.; Mills, K.I.; et al. HOXA/PBX3 knockdown impairs growth and sensitizes cytogenetically normal acute myeloid leukemia cells to chemotherapy. Haematologica 2013, 98, 1216-1225. [CrossRef] [PubMed]

23. Ferrando, A.A.; Armstrong, S.A.; Neuberg, D.S.; Sallan, S.E.; Silverman, L.B.; Korsmeyer, S.J.; Look, A.T. Gene expression signatures in MLL-rearranged T-lineage and B-precursor acute leukemias: Dominance of HOX dysregulation. Blood 2003, 102, 262-268. [CrossRef] [PubMed]

24. Haferlach, C.; Haferlach, T. Another piece of the AML puzzle. Blood 2013, 122, 2532-2534. [CrossRef]

25. Milne, T.A.; Martin, M.E.; Brock, H.W.; Slany, R.K.; Hess, J.L. Leukemogenic MLL fusion proteins bind across a broad region of the Hox a9 locus, promoting transcription and multiple histone modifications. Cancer Res. 2005, 65, 11367-11374. [CrossRef]

26. Ayton, P.M.; Cleary, M.L. Transformation of myeloid progenitors by MLL oncoproteins is dependent on Hoxa7 and Hoxa9. Genes Dev. 2003, 17, 2298-2307. [CrossRef]

27. Kumar, A.R.; Hudson, W.A.; Chen, W.; Nishiuchi, R.; Yao, Q.; Kersey, J.H. Hoxa9 influences the phenotype but not the incidence of Mll-AF9 fusion gene leukemia. Blood 2004, 103, 1823-1828. [CrossRef]

28. So, C.W.; Karsunky, H.; Wong, P.; Weissman, I.L.; Cleary, M.L. Leukemic transformation of hematopoietic progenitors by MLL-GAS7 in the absence of Hoxa7 or Hoxa9. Blood 2004, 103, 3192-3199. [CrossRef]

29. Kmita, M.; Tarchini, B.; Zakany, J.; Logan, M.; Tabin, C.J.; Duboule, D. Early developmental arrest of mammalian limbs lacking HoxA/HoxD gene function. Nature 2005, 435, 1113-1116. [CrossRef]

30. Chen, E.Y.; Tan, C.M.; Kou, Y.; Duan, Q.N.; Wang, Z.C.; Meirelles, G.V.; Clark, N.R.; Ma'ayan, A. Enrichr: Interactive and collaborative HTML5 gene list enrichment analysis tool. BMC Bioinform. 2013, 14. [CrossRef]

31. Kuleshov, M.V.; Jones, M.R.; Rouillard, A.D.; Fernandez, N.F.; Duan, Q.; Wang, Z.; Koplev, S.; Jenkins, S.L.; Jagodnik, K.M.; Lachmann, A.; et al. Enrichr: A comprehensive gene set enrichment analysis web server 2016 update. Nucleic Acids Res. 2016, 44, W90-W97. [CrossRef] [PubMed] 
32. Bower, H.; Bjorkholm, M.; Dickman, P.W.; Hoglund, M.; Lambert, P.C.; Andersson, T.M. Life Expectancy of Patients With Chronic Myeloid Leukemia Approaches the Life Expectancy of the General Population. J. Clin. Oncol. 2016, 34, 2851-2857. [CrossRef] [PubMed]

33. Grier, D.G.; Thompson, A.; Kwasniewska, A.; McGonigle, G.J.; Halliday, H.L.; Lappin, T.R. The pathophysiology of HOX genes and their role in cancer. J. Pathol. 2005, 205, 154-171. [CrossRef] [PubMed]

34. Alharbi, R.A.; Pettengell, R.; Pandha, H.S.; Morgan, R. The role of HOX genes in normal hematopoiesis and acute leukemia. Leukemia 2013, 27, 1000-1008. [CrossRef]

35. Crooks, G.M.; Fuller, J.; Petersen, D.; Izadi, P.; Malik, P.; Pattengale, P.K.; Kohn, D.B.; Gasson, J.C. Constitutive HOXA5 expression inhibits erythropoiesis and increases myelopoiesis from human hematopoietic progenitors. Blood 1999, 94, 519-528. [CrossRef]

36. Fuller, J.F.; McAdara, J.; Yaron, Y.; Sakaguchi, M.; Fraser, J.K.; Gasson, J.C. Characterization of HOX gene expression during myelopoiesis: Role of HOX A5 in lineage commitment and maturation. Blood 1999, 93, 3391-3400. [CrossRef]

37. Dickson, G.J.; Kwasniewska, A.; Mills, K.I.; Lappin, T.R.; Thompson, A. Hoxa6 potentiates short-term hemopoietic cell proliferation and extended self-renewal. Exp. Hematol. 2009, 37, 322-333. [CrossRef]

38. Magnusson, M.; Brun, A.C.; Miyake, N.; Larsson, J.; Ehinger, M.; Bjornsson, J.M.; Wutz, A.; Sigvardsson, M.; Karlsson, S. HOXA10 is a critical regulator for hematopoietic stem cells and erythroid/megakaryocyte development. Blood 2007, 109, 3687-3696. [CrossRef]

39. Lawrence, H.J.; Helgason, C.D.; Sauvageau, G.; Fong, S.; Izon, D.J.; Humphries, R.K.; Largman, C. Mice bearing a targeted interruption of the homeobox gene HOXA9 have defects in myeloid, erythroid, and lymphoid hematopoiesis. Blood 1997, 89, 1922-1930. [CrossRef]

40. Magnusson, M.; Brun, A.C.; Lawrence, H.J.; Karlsson, S. Hoxa9/hoxb3/hoxb4 compound null mice display severe hematopoietic defects. Exp. Hematol. 2007, 35, 1421-1428. [CrossRef]

41. Thorsteinsdottir, U.; Mamo, A.; Kroon, E.; Jerome, L.; Bijl, J.; Lawrence, H.J.; Humphries, K.; Sauvageau, G. Overexpression of the myeloid leukemia-associated Hoxa9 gene in bone marrow cells induces stem cell expansion. Blood 2002, 99, 121-129. [CrossRef] [PubMed]

42. Faber, J.; Krivtsov, A.V.; Stubbs, M.C.; Wright, R.; Davis, T.N.; van den Heuvel-Eibrink, M.; Zwaan, C.M.; Kung, A.L.; Armstrong, S.A. HOXA9 is required for survival in human MLL-rearranged acute leukemias. Blood 2009, 113, 2375-2385. [CrossRef] [PubMed]

43. Horton, S.J.; Grier, D.G.; McGonigle, G.J.; Thompson, A.; Morrow, M.; De Silva, I.; Moulding, D.A.; Kioussis, D.; Lappin, T.R.; Brady, H.J.; et al. Continuous MLL-ENL expression is necessary to establish a "Hox Code" and maintain immortalization of hematopoietic progenitor cells. Cancer Res. 2005, 65, 9245-9252. [CrossRef] [PubMed]

44. Jin, N.; Yang, L.Y.; Xu, Z.P. Long non-coding RNA HOTTIP is able to predict poor prognosis in various neoplasms: A meta-analysis. Mol. Clin. Oncol. 2017, 7, 263-266. [CrossRef] [PubMed]

45. Fang, Y.; Wang, J.; Wu, F.; Song, Y.; Zhao, S.; Zhang, Q. Long non-coding RNA HOXA-AS2 promotes proliferation and invasion of breast cancer by acting as a miR-520c-3p sponge. Oncotarget 2017, 8, 46090-46103. [CrossRef] [PubMed]

46. Lebert-Ghali, C.E.; Fournier, M.; Kettyle, L.; Thompson, A.; Sauvageau, G.; Bijl, J.J. Hoxa cluster genes determine the proliferative activity of adult mouse hematopoietic stem and progenitor cells. Blood 2016, 127, 87-90. [CrossRef]

47. Maraka, S.; Groves, M.D.; Mammoser, A.G.; Melguizo-Gavilanes, I.; Conrad, C.A.; Tremont-Lukats, I.W.; Loghin, M.E.; O’Brien, B.J.; Puduvalli, V.K.; Sulman, E.P.; et al. Phase 1 lead-in to a phase 2 factorial study of temozolomide plus memantine, mefloquine, and metformin as postradiation adjuvant therapy for newly diagnosed glioblastoma. Cancer 2019, 125, 424-433. [CrossRef]

48. Nolte, E.; Wach, S.; Silva, I.T.; Lukat, S.; Ekici, A.B.; Munkert, J.; Muller-Uri, F.; Kreis, W.; Oliveira Simoes, C.M.; Vera, J.; et al. A new semisynthetic cardenolide analog 3beta-[2-(1-amantadine)1-on-ethylamine]-digitoxigenin (AMANTADIG) affects G2/M cell cycle arrest and miRNA expression profiles and enhances proapoptotic survivin-2B expression in renal cell carcinoma cell lines. Oncotarget 2017, 8, 11676-11691. [CrossRef]

49. Foreman, K.E.; Jesse, J.N.; Kuo, P.C.; Gupta, G.N. Emetine dihydrochloride: A novel therapy for bladder cancer. J. Urol. 2014, 191, 502-509. [CrossRef] 
50. Yosifov, D.Y.; Idler, I.; Bhattacharya, N.; Reichenzeller, M.; Close, V.; Ezerina, D.; Scheffold, A.; Jebaraj, B.M.C.; Kugler, S.; Bloehdorn, J.; et al. Oxidative stress as candidate therapeutic target to overcome microenvironmental protection of CLL. Leukemia 2019. [CrossRef]

51. Mill, C.P.; Fiskus, W.; DiNardo, C.D.; Qian, Y.; Raina, K.; Rajapakshe, K.; Perera, D.; Coarfa, C.; Kadia, T.M.; Khoury, J.D.; et al. RUNX1-targeted therapy for AML expressing somatic or germline mutation in RUNX1. Blood 2019, 134, 59-73. [CrossRef] [PubMed]

52. Goyama, S.; Schibler, J.; Cunningham, L.; Zhang, Y.; Rao, Y.; Nishimoto, N.; Nakagawa, M.; Olsson, A.; Wunderlich, M.; Link, K.A.; et al. Transcription factor RUNX1 promotes survival of acute myeloid leukemia cells. J. Clin. Investig. 2013, 123, 3876-3888. [CrossRef] [PubMed]

53. Morrow, M.; Horton, S.; Kioussis, D.; Brady, H.J.; Williams, O. TEL-AML1 promotes development of specific hematopoietic lineages consistent with preleukemic activity. Blood 2004, 103, 3890-3896. [CrossRef] [PubMed]

54. Vormoor, B.; Knizia, H.K.; Batey, M.A.; Almeida, G.S.; Wilson, I.; Dildey, P.; Sharma, A.; Blair, H.; Hide, I.G.; Heidenreich, O.; et al. Development of a preclinical orthotopic xenograft model of ewing sarcoma and other human malignant bone disease using advanced in vivo imaging. PLoS ONE 2014, 9, e85128. [CrossRef]

55. Roulston, G.D.; Burt, C.L.; Kettyle, L.M.; Matchett, K.B.; Keenan, H.L.; Mulgrew, N.M.; Ramsey, J.M.; Dougan, C.; McKiernan, J.; Grishagin, I.V.; et al. Low-dose salinomycin induces anti-leukemic responses in AML and MLL. Oncotarget 2016, 7, 73448-73461. [CrossRef]

56. Dunning, M.J.; Smith, M.L.; Ritchie, M.E.; Tavare, S. beadarray: R classes and methods for Illumina bead-based data. Bioinformatics 2007, 23, 2183-2184. [CrossRef]

57. Ritchie, M.E.; Phipson, B.; Wu, D.; Hu, Y.; Law, C.W.; Shi, W.; Smyth, G.K. limma powers differential expression analyses for RNA-sequencing and microarray studies. Nucleic Acids Res. 2015, 43, e47. [CrossRef]

(C) 2019 by the authors. Licensee MDPI, Basel, Switzerland. This article is an open access article distributed under the terms and conditions of the Creative Commons Attribution (CC BY) license (http://creativecommons.org/licenses/by/4.0/). 